\title{
UMA PROPOSTA DIALÓGICA PARA O LETRAMENTO LITERÁRIO
}

\author{
Helio Castelo Branco Ramos
}

\begin{abstract}
RESUMO
Com base nos estudos do Círculo de Bakhtin, nosso objetivo é refletir sobre uma proposta de letramento literário articulada ao letramento de gêneros discursivos pragmáticos, como notícias e reportagens que circulam na esfera digital, de modo que essa articulação ajude a desenvolver também de forma integrada habilidades no âmbito da oralidade, escrita, leitura e reflexão linguística.

PALAVRAS-CHAVE: Círculo de Bakhtin; letramento literário; habilidades linguísticas.
\end{abstract}

\section{Introdução}

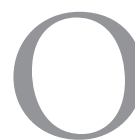

letramento literário tem sido alvo de vários embates acadêmicos, que incluem desde o questionamento de quais seriam as abordagens teórico-metodológicas mais adequadas até quais textos (canônicos, da cultura de massa, de outras esferas sociais, etc) deveriam figurar nas aulas. No tocante à questão teórico-metodológica, alguns pesquisadores, entre eles, Aguiar e Bordini (1993), Lajolo (1994) e Pinheiro (2009), criticam a ênfase dada ao ensino de características gerais que compóem cada estética literária. Para esses pesquisadores, a formação do leitor deve enfatizar a leitura de textos literários em vez de apenas se resumir a um estudo sobre as obras que seriam representativas de um determinado estilo de época.

A formação do leitor de textos literários (ou mesmo de textos não literários) é uma tarefa que demanda do professor a articulação de diversos saberes. Esses saberes incluem desde conhecimentos específicos, como o domínio do 
objeto de ensino, passando por conhecimentos ligados às teorias da aprendizagem, até conhecimentos que são adquiridos na experiência docente (TARDIF, 2007). Esses diferentes conhecimentos são complementares, e cada um deles ilumina determinado aspecto da prática docente. Diante da impossibilidade de tratar da contribuição de todos eles para o letramento literário (sem correr o risco de abordarmos o tema superficialmente), iremos nos deter às contribuiçôes presentes nos estudos bakhtinianos.

Julgamos ser indissociável do debate sobre letramento literário a reflexão sobre o que é compreensão leitora, pois o conceito que o docente possui acerca do processo de compreensão poderá influenciar a maneira pela qual irá propor a interação entre o aluno e o texto literário. Em outras palavras, a depender do conceito que o professor possui sobre compreensão leitora, poderá julgar que ela se resume à decodificação da materialidade linguística de um texto.

Nosso trabalho pretende não dicotomizar a relação entre teoria e prática. Para tanto, inicialmente, considerando algumas ideias presentes nos estudos do Círculo de Bakhtin, refletiremos sobre a relação entre conceito de língua(gem) e de compreensão leitora. Em segundo lugar, descreveremos uma proposta de abordagem para o letramento literário com base nessas ideias. Por fim, faremos algumas consideraçóes acerca de nossa proposta.

\section{Concepção dialógica de língua(gem) e compreensão leitora}

É possível opor a concepção dialógica de língua(gem) a duas concepçôes. A primeira, cujos fundamentos poderíamos associar aos estoicos (ARAÚJO, 2004), corresponderia a um "instrumento" cuja função seria externalizar o que um indivíduo pensa. A segunda, de base saussuriana, representaria um conjunto de signos constituídos por meio de uma convençáo social e cujo sentido se encerra numa relação de oposição entre eles. É possível perceber que ambas as concepçóes dão relevo a algum aspecto do processo de interação entre os sujeitos. A primeira reduz a língua(gem) a um uso individual de cada sujeito, já a segunda fica centrada no sistema linguístico em si.

Esses dois conceitos também são responsáveis por duas maneiras de conceber o processo de compreensão leitora. O primeiro pode nos levar à ideia de que o processo de compreensão leitora de um texto literário corresponde à identificação do que o autor queria dizer ao escrever seu texto. $\mathrm{O}$ segundo, por 
seu turno, pode fazer com que acreditemos que a compreensão de um texto literário se resume à decodificação de seus aspectos linguísticos. Nenhum dos dois conceitos pode dar conta do fenômeno da compreensão, porque ambos ficam presos a um único elemento do processo de interação entre os sujeitos.

De acordo com as ideias do Círculo de Bakhtin, não é possível isolar a relação entre pensamento e língua(gem) em dois momentos, pois o pensamento em si já é constituído por material semiótico. Por outro lado, uma forma linguística sempre se apresenta aos interlocutores no contexto de enunciaçóes relativamente estáveis, de modo que está ligada intrinsecamente a um contexto ideológico também relativamente estável. Por conta disso, Volochínov afirma que "não são palavras o que pronunciamos ou escutamos, mas verdades ou mentiras, coisas boas ou más, importantes ou triviais, agradáveis ou desagradáveis, etc. A palavra está sempre carregada de um conteúdo ou de um sentido ideológico ou vivencial' ([1929] 2009, p. 98-99, grifo do autor).

Essa impossibilidade de separar a palavra de seu caráter ideológico faz com que, ao estudar a língua(gem), reconheçamos que o conhecimento mantém uma relação intrínseca com contextos históricos e culturais específicos, e que as atividades intelectuais são atravessadas por peculiaridades institucionais e por uma dimensão ética (um posicionamento axiológico) que tem sua visada na língua(gem) e em seu papel nas atividades humanas.

Desse modo, para o Círculo, a realidade da língua(gem) é o discurso, ou seja, um evento de língua(gem) cujo sentido só pode ser construído caso levemos em consideração quem são os sujeitos envolvidos em determinada interação, em que espaço e tempo essa interação se dá, que posicionamentos esses sujeitos assumem em relação ao objeto de seus discursos, etc. Contudo, o discurso não é o "lugar" do caos, pois ele possui uma organização relativamente estável que ajuda os sujeitos a produzirem-no e compreenderem-no. Essa organização dos discursos que tem por base seu tema, sua composição e estilo, além das condiçôes de produção e compreensão de determinado ramo da atividade humana, Bakhtin nomeou de gênero discursivo.

Assumir que o discurso é a língua(gem) em sua concretude implica aceitar a noção de que ela é dialógica por natureza. Segundo Volochínov, "pode-se compreender a palavra 'diálogo' num sentido amplo, isto é, não apenas como a comunicação em voz alta, de pessoas colocadas face a face, mas toda comunicação verbal, de qualquer tipo que seja” (Volochínov, [1929] 2009, p. 127). 
Para o Círculo, o diálogo face a face é apenas um protótipo do que acontece em qualquer interação, isto é, nosso discurso sempre é uma réplica para o discurso de outrem. Nesse sentido, ao produzirmos um discurso, estaremos sempre produzindo uma relação com discursos anteriores ao nosso, para concordar com eles, discordar deles, parodiá-los, estilizá-los, entre outras possibilidades. Ao mesmo tempo em que apresentamos uma réplica a um discurso anterior, nosso discurso também fica sujeito à réplica de terceiros, gerando, assim, uma cadeia ininterrupta de discursos.

Conceber a língua(gem) sob o viés do dialogismo faz com que aceitemos a ideia de que "toda compreensão é prenhe de resposta, e nessa ou naquela forma a gera obrigatoriamente: o ouvinte se torna falante" (BAKHTIN, [1952-1953] 2011, p. 271). Com isso, o processo de compreensão leitora não pode ser visto apenas como a busca das intençôes do autor do texto literário ou mera decodificação da materialidade linguística de uma obra, porque essas noções minimizam o papel ativo do leitor. A compreensão leitora é, antes de tudo, um processo de interação, porque autor, texto e leitor são igualmente importantes na construção de sentido. Poderíamos dizer que o autor constrói uma obra para que ela possua uma "linguagem carregada de significado" (para lembrarmos Pound) e, por essa razão, há uma série de não ditos nela, que o leitor precisa recuperar. Vale salientar, no entanto, que o leitor não constrói o sentido de forma aleatória, mas a partir dos ditos que uma obra possui. Poderíamos dizer que os leitores vão traçando diferentes percursos pelos ditos da obra, de modo que diferentes interpretaçóes são geradas, dando, assim, "manutenção" à sua polissemia.

\section{Nossa proposta teórico-metodológica}

A concepção de língua(gem) presente nos estudos do Círculo de Bakhtin pode nos dar algumas pistas de como desenvolver uma proposta de letramento literário. Uma das principais perguntas a serem feitas, a fim de desenvolvermos tal proposta, é: o que nós, professores, queremos com o letramento literário?

Uma afirmação de Medviédev pode nos ajudar a formular uma resposta para esse questionamento: "É possível dizer que a consciência humana possui uma série de gêneros interiores que servem para ver e compreender a realidade. Dependendo do meio ideológico, uma consciência é mais rica em gêneros, 
enquanto outra é mais pobre" ([1928] 2012, p. 198). Trata-se de uma importante reflexão sobre o papel da língua(gem) no amadurecimento da percepção humana, pois, sendo nossa consciência constituída por língua(gem), o que vemos e compreendemos sobre o mundo está diretamente relacionado com os gêneros discursivos que somos capazes de compreender e produzir. Nesse sentido, os gêneros discursivos não são apenas constituídos pelas condições de produção de determinado ramo da atividade humana, mas também as constituem, de maneira que o modo como "conduzimos" nossa existência está permeado pela língua(gem).

De acordo com Freire (1992), todo ser humano já compreende o mundo que o cerca, porém o conhecimento da palavra faz com que passemos a compreender o mundo a partir de novas perspectivas. O caminho inverso também acontece, isto é, a partir de novas perspectivas sobre o mundo, nosso olhar sobre a palavra também se potencializa. Ou seja, quando passamos a tomar contato com discursos da cultura letrada, temos a possibilidade de superar o senso comum sobre a realidade. Através da superação do senso comum, também passamos a analisar os discursos produzidos pela cultura letrada com um olhar mais analítico.

Ainda no tocante à relação entre língua(gem), mundo e percepção, cumpre mencionarmos os estudos dos Formalistas Russos, que são muitas vezes retomados pelo Círculo de Bakhtin. Segundo Chklovski, nossa percepção, quando constituída pela língua cotidiana, encontra-se imersa em automatismos, já que essa língua, como é voltada à comunicação entre os sujeitos, procura torná-la "eficiente" ao máximo, garantindo um esforço perceptivo mínimo das coisas do mundo. Assim, para que um texto seja considerado artístico, precisa ser construído de uma forma que cause estranhamento ao leitor. Em outras palavras, o texto literário precisa apresentar uma configuração das formas linguísticas diferente daquela com a qual estamos habituados a lidar cotidianamente - a língua poética -, a fim de que essa nova configuração resulte igualmente numa mudança perceptiva no que se refere aos aspectos cotidianos mimetizados.

A nosso ver, a maneira como os formalistas concebem a função da leitura literária, isto é, tirar o ser humano do automatismo perceptivo no qual se encontra imerso, aponta para nós, professores, qual o objetivo do letramento literário: ajudar o aluno a compreender que o modo como o autor de uma obra li- 
terária organizou a simbologia de seu discurso busca criar desvelamentos sobre a condição humana que, até então, estavam fora de nosso alcance perceptivo.

Contudo, o modo dicotômico como os formalistas separam os textos literários (a língua poética) de todos os outros textos não literários (resumidos a uma língua cotidiana) não parece traduzir o fenômeno da estratificação da língua(gem) em diferentes práticas discursivas, diferentes gêneros discursivos, registros, estilos, etc. Além disso, outras práticas discursivas, como a filosofia, a religião, a ciência, o jornalismo, etc, são constitutivas do discurso literário. Assim, não cremos ser possível advogar a "pureza" de uma prática discursiva, pois a natureza da língua(gem) é dialógica.

Nesse ponto, caberia uma segunda pergunta: como ajudar, então, nossos alunos a se letrar literariamente partindo das ideias do Círculo de Bakhtin? Considerando que a realidade da língua(gem) é o discurso e que todo discurso estabelece uma relação dialógica com outros discursos, parece-nos que o letramento literário não pode acontecer apartado de outras práticas de letramento. Afinal, como nossa percepção é constituída por uma diversidade de gêneros discursivos, inclusive os gêneros da oralidade, é preciso refletir com nossos alunos sobre como essa diversidade de gêneros ajuda na construção de nossa subjetividade. Por exemplo, que concepção temos sobre a passagem do tempo ao lermos uma reportagem acerca de novos métodos para rejuvenescimento? Que concepção temos sobre a mesma temática ao lermos a poesia de Cecília Meireles? O que o discurso filosófico tem a nos oferecer sobre essa questão?...

A fim de corporificar como seria um trabalho de leitura dessa natureza, apresentamos a seguir a discussáo de uma proposta de abordagem para uma turma do primeiro ano do Ensino Médio de uma escola pública. Primeiramente, definimos como temática a relação do ser humano com inovações tecnológicas. Em seguida, decidimos que habilidades desenvolver no âmbito da leitura, reflexão linguística e produção textual. Por fim, escolhemos os textos e o tempo dedicado à sequência didática. Vale salientar que essa ordem não precisa, necessariamente, ser cumprida à risca, porém é preciso levar em conta esses aspectos na elaboração de uma sequência didática. Nossa sequência é constituída por quatro etapas.

Na primeira etapa, que pode levar de 2 a 4 horas-aula a depender do grupo-classe, inicialmente, devemos explicar para os alunos que iremos desenvolver atividades de leitura, reflexão sobre o uso da língua e produção de texto, 
a fim de compreender como nós, seres humanos, temos nos relacionado com as inovaçóes tecnológicas. Realizada essa explicação, faríamos um momento de mobilização com os alunos, perguntando-lhes o que pensam a respeito do avanço da tecnologia. Em seguida, leríamos uma notícia publicada num blog voltado a usuários de iphones ${ }^{1}$.

Antes de lermos a notícia, poderíamos mostrar as imagens a seguir, para que os alunos levantassem algumas hipóteses iniciais sobre o conteúdo da notícia. Perguntaríamos em que local possivelmente as pessoas se encontram, por que estão nessa fila, o que significa o uso dessa pulseira no braço. E, principalmente, o que tudo isso teria a ver com a maneira pela qual nos relacionamos com a tecnologia.
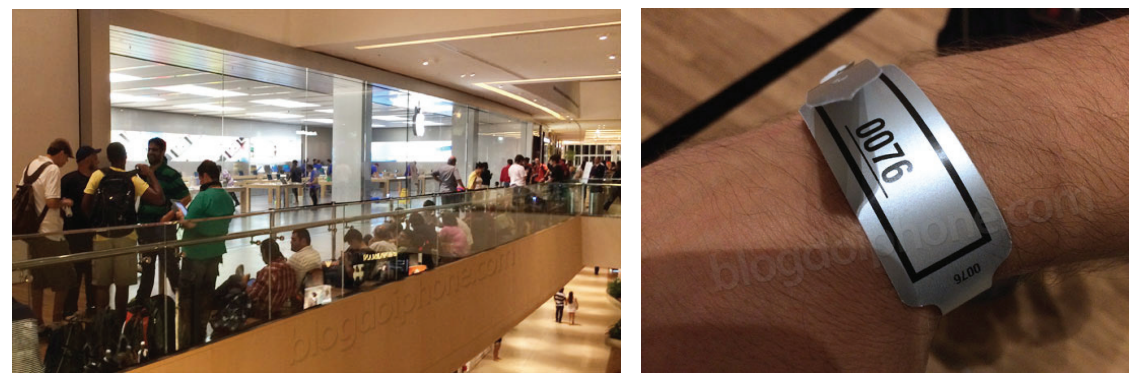

Em seguida, exibiríamos a notícia na íntegra, se possível através de uma projeção do blog de onde foram retiradas suas imagens. Nosso objetivo com a leitura da notícia é ensinar os alunos a perceber o posicionamento discursivo de seus autores. Para isso, pediríamos para que os alunos examinassem o título da notícia - Brasileiros dormem na fila para inauguração da Apple Store no Rio - e levantassem novas hipóteses antes de ler o corpo do texto, entre elas, qual seria a razão desses brasileiros dormirem na fila para a inauguração da Apple. Poderíamos igualmente questionar os alunos se eles dormiriam numa fila como essa e por que. Depois de ler a notícia em voz alta junto com os alunos, eles a analisariam, a fim de descobrir por que esses brasileiros dormiram nessa fila e o que os autores da notícia pensam sobre essa atitude. Alguns aspectos linguísticos poderiam ser apontados, como, por exemplo, as predicaçóes a seu respeito da Apple: "apresentou seu típico padrão internacional” e "começou a

1 Disponível em <http://blogdoiphone.com/2014/02/brasileiros-dormem-na-fila-para-a-inauguracao-da-apple-store-do-rio/>. Acesso em 30/06/2015. 
distribuir braceletes com senhas numeradas, para que todos pudessem ser encaminhados a uma sala reservada [a fim de se acomodarem] confortavelmente e até tirassem uma sonequinha”. Além disso, os alunos poderiam ler no blog a aba "quem somos", na qual os autores se definem como pessoas que desenvolveram um blog que "tornou-se referência para outros sites brasileiros e estrangeiros quando o assunto é Apple", a fim de confrontar com as predicaçóes que os autores fizeram para a Apple. Assim, seria possível perceber que os autores são entusiastas da atitude dos brasileiros que dormiram na fila.

$\mathrm{Na}$ segunda etapa, que também pode durar de 2 a 4 horas-aula, nosso objetivo é refletir com os alunos que o entusiasmo do ser humano com inovaçôes tecnológicas é antigo, a partir de uma notícia comemorativa dos 40 anos da ida do homem à lua e de depoimentos de pessoas que vivenciaram esse momento na qualidade de espectadores ${ }^{2}$. $\mathrm{Na}$ mobilizaçáo para a leitura, perguntaríamos para os alunos se eles conhecem alguma inovaçáo tecnológica que tenha marcado a história da humanidade. Em seguida, leríamos a notícia e perguntaríamos aos alunos que posicionamento eles esperam ouvir dos entrevistados, para comparar suas hipóteses iniciais com os discursos que iriam ouvir. Para que os alunos pudessem perceber o posicionamento dos entrevistados, seria possível explorar novamente aspectos linguísticos, como as predicaçóes utilizadas para falar sobre o evento, e aspectos discursivos, como é o caso da entonação entusiasmada de alguns entrevistados. Num momento de pós-leitura, poderíamos pedir para que os alunos comparassem a atitude dos entrevistados com a atitude dos brasileiros que dormiram na fila aguardando a inauguração da Apple e perguntar o acham disso tudo.

$\mathrm{Na}$ terceira etapa, que pode, como as anteriores, durar de 2 a 4 horas-aula, seria o momento de pôr em diálogo o letramento de notícias com o letramento literário através da leitura do poema "O homem; as viagens", de Drummond $^{3}$. Seria o momento também de pôr em diálogo os discursos anteriores com o discurso do poeta, a fim de analisar que percepçáo ele nos proporciona sobre a temática que viemos discutindo durante as aulas. Antes

2 Tanto a notícia quanto os depoimentos encontram-se disponíveis num hotsite do jornal Diário de Pernambuco: http://www.old.diariodepernambuco.com.br/hotsite/2009/ lua_40anos/inicial.shtml. Acesso em 30/06/2015.

3 Disponível em <http://www.algumapoesia.com.br/drummond/drummond05.htm>. Acesso em 30/06/2015. 
da leitura do poema, relembraríamos como os autores das notícias e dos depoimentos se posicionaram em relação à temática e perguntaríamos aos alunos qual sua expectativa em relação ao posicionamento do poeta. Nesse ponto, caberia questionar se eles conhecem Drummond, se já leram algum de seus poemas, se conhecem os temas mais recorrentes de sua poesia, etc, a fim de contextualizar sua produção poética.

Ainda antes da leitura do poema, poderíamos escrever seu título no quadro e questionar os alunos sobre o uso do ponto e vírgula em vez da conjunção "e". Caso os alunos nâo soubessem explicitar a ideia de oposiçấo criada por esse recurso, caber-nos-ia explicar-lhes e questioná-los sobre que tipo de oposição poderia existir entre o homem e as viagens ou ainda a que tipo de viagens se refere o poeta. Depois de declamarmos o poema, de modo que o aluno pudesse perceber (em discussão oral posterior) que o ritmo dos versos desse poema tem uma relação direta com alguns efeitos de sentido, poderíamos dividi-los em duplas ou trios, para análise do texto com base num estudo dirigido.

No estudo dirigido, vários aspectos poderiam ser analisados, de modo que chamaremos atenção para alguns: a) que lugares são visitados pelo homem descrito no poema?; b) que razão ele tem para realizar a primeira viagem ao primeiro local? E em relaçấo aos demais locais?; c) por que há uma série de construçốes no texto que sugerem uma repetição?; d) se comparada às outras estrofes, a sexta possui um ritmo mais lento. O que esse fato revela em relação ao seu conteúdo?; e) afinal, a que tipo de viagens opostas o poeta se refere? Durante a discussão sobre o poema, essas perguntas serviriam de base para que os alunos concluíssem que Drummond, por meio desse texto, levanta a suspeita de que, entre outros aspectos, nós, seres humanos, somos capazes de produzir grandes feitos tecnológicos, porém não somos capazes de explorar nossa subjetividade ou ainda não somos capazes de "con-viver" uns com os outros. Finalizada a discussão sobre o poema, caberia perguntar aos alunos de que modo Drummond ressignificou (ou não) seu olhar para a questão da tecnologia e por que razão.

$\mathrm{Na}$ etapa final, que estimamos durar de 2 a 6 horas-aula, caberia agora voltarmos à notícia do blog para que os alunos tivessem a oportunidade de se posicionar também a partir da escrita. Como mobilização, perguntaríamos se eles perceberam que há comentários acerca da notícia e qual seria o possível teor desses comentários. Na sequência, leríamos os comentários para 
analisar de que modo os leitores se posicionaram em relação ao conteúdo da notícia. Em seguida, os alunos poderiam escolher comentar a notícia ou responder a algum comentário. Escolhida a maneira de participar, solicitaríamos que os alunos escrevessem uma versão preliminar do comentário. Concluída a versão preliminar, pediríamos que, reunidos em dupla, avaliassem a qualidade dos argumentos levantados pelo colega, a fim de sugerir alguma modificação. Finalizada a revisão dos argumentos, pediríamos para que os alunos fizessem uma análise da adequação linguística dos comentários à norma padrão. Depois de concluído todo o processo de revisão, publicaríamos os comentários no blog.

\section{Considerações finais}

Toda concepção de língua(gem) aponta para um modo de encarar o processo de interação entre os sujeitos. Nossa perspectiva sobre esse processo, por seu turno, igualmente contribui para os pressupostos que orientam nossa proposta teórico-metodológica de letramento literário. A concepção dialógica de língua(gem) nos faz pensar que o letramento literário, sobretudo no caso do Brasil (que ainda apresenta altos índices de analfabetismo e analfabetismo funcional), não pode acontecer apartado de outras práticas de letramento, pois o texto literário demanda o diálogo com outros discursos, para que possamos compreendê-lo. Isso, porque, como os demais textos, o texto literário apresenta uma resposta (no sentido bakhtiniano) a outros discursos, sejam literários ou não.

No tocante às competências e habilidades ligadas ao ensino de língua(gem), embora tenhamos focado em nossa proposta de letramento literário a questão da compreensão leitora, também a relacionamos com o ensino de reflexão linguística e produção textual, porque acreditamos, por um lado, que a reflexão linguística é constitutiva da leitura e da escrita, e, por outro, que a produção textual implica no posicionamento dos alunos. Assim, cremos conseguir um equilíbrio entre o (re)conhecimento do posicionamento axiológico de outrem e a possibilidade de também se posicionar.

Contudo, vale salientar que essa proposta de articular o discurso literário com outros discursos não visa dizer que ele não possui especificidade. Pelo contrário, essa articulação visa dar maior evidência ao seu projeto de dizer 
em relação ao projeto de outros discursos. Se considerarmos, por exemplo, os textos que sugerimos em nossa proposta, o de Drummond parece apresentar um questionamento mais profundo sobre o real, dando-nos a possibilidade de romper com nossos automatismos.

\section{Referências}

AGUIAR, Vera Teixeira de.; BORDINI, Maria da Glória. Literatura: a formação do leitor. Alternativas metodológicas. 2. ed. Porto Alegre: Mercado Aberto, 1993.

ARAÚJO, Inês Lacerda. Do signo ao discurso: introdução à filosofia da linguagem. São Paulo: Parábola, 2004.

BAKHTIN, Mikhail Mikhailovitch. Os gêneros do discurso. In: Estética da criação verbal. Tradução direta do russo de Paulo Bezerra. 6. ed. São Paulo: Martins Fontes, [1952-1953] 2011.p. 261-306.

CHKLOVSKI, Viktor. A arte como procedimento. In: TOLEDO, Dionísio de Oliveira. (Org.). Teoria da literatura: formalistas russos. 2. ed. Porto Alegre: [1917] 1976. cap. 1, p. 39-56.

FREIRE, Paulo. A importância do ato de ler: em três artigos que se completam. 27. ed. São Paulo: Cortez, 1992.

LAJOLO, Marisa. Do mundo da leitura para a leitura do mundo. 6. ed. São Paulo: Ática, 2010.

MEDVIÉDEV, Pável Nikoláievitch. O método formal nos estudos literários: introdução crítica a uma poética sociológica. São Paulo: Contexto, [1928] 2012.

PINHEIRO, Hélder. Reflexôes sobre o livro didático de literatura. In: BUNZEN, Clécio; MENDONÇA, Márcia. Português no ensino médio e formação do professor. 3. ed. São Paulo: Parábola, 2009. cap. 6, p. 103-116.

TARDIF, Maurice. Saberes docentes e formação profissional. 8. ed. Rio de Janeiro: Vozes, 2007.

VOLOCHÍNOV, Valentin Nikolaevich. Marxismo e filosofia da linguagem. Trad. de Michel Lahud e Yara Frateschi Vieira. 13. ed. São Paulo: Hucitec, [1929] 2009. 


\title{
A DIALOGIC PROPOSAL TO LITERARY LITERACY
}

\begin{abstract}
Based on Bakhtin's Circle' studies, we reflect about a proposal of literary literacy on which teachers can teach abilities on orality, writing, reading and linguistic aspects reflection to their students in an integrated way. Therefore, our proposal of literary literacy is combined with the pragmatic discourse genres literacy, such as news found in digital sphere.

KEYWORDS: Bakhtin's Circle; literary literacy; linguistic abilities.
\end{abstract}

Recebido em: 31/10/2015

Aprovado em: 28/03/2016 